\title{
Multi-Model Approaches to Phylogenetics: Implications for Idealization
}

\author{
Aja Watkins \\ Forthcoming in Studies in History and Philosophy of Science, 2021
}

\begin{abstract}
Phylogenetic models traditionally represent the history of life as having a strictlybranching tree structure. However, it is becoming increasingly clear that the history of life is often not strictly-branching; lateral gene transfer, endosymbiosis, and hybridization, for example, can all produce lateral branching events. There is thus motivation to allow phylogenetic models to have a reticulate structure. One proposal involves the reconciliation of genealogical discordance. Briefly, this method involves using patterns of disagreement - discordance - between trees of different genes to add lateral branching events to phylogenetic trees of taxa, and to estimate the most likely cause of these events. I use this practice to argue for: (1) a need for expanded accounts of multiplemodels idealization, (2) a distinction between automatic and manual de-idealization, and (3) recognition that idealization may serve the meso-level aims of science in a different way than hitherto acknowledged.
\end{abstract}

Keywords - phylogenetics, idealization, genealogical discordance, lateral gene transfer, hybridization

\section{Introduction}

Phylogenetic models are a crucial tool for understanding the history of life on Earth. The theory of evolution by natural selection itself may suggest that the history of life has a strictly-branching structure, in which populations diverge as the result of accumulated variation over time. However, in recent decades it has become apparent that the history of life does not have a strictly-branching structure, because numerous instances of merging or genetic exchange between otherwise disconnected lineages have been reported. Incorporating these instances into the tree of life would give this tree a reticulate structure. If we want our phylogenetic models to be accurate, they have to allow for reticulation, when appropriate. Yet, the historically dominant methods for constructing phylogenetic models explicitly disallow lateral branches. 
Biologists and philosophers have espoused many solutions to this problem, including suggesting a departure between the explanatory target of phylogenetics and historical reconstructions or recommending new algorithms that allow for lateral branches. One suggestion which has received recent philosophical attention is the thought that disagreement between phylogenetic trees constructed on the basis of gene histories, a phenomenon known as genealogical discordance, can be used as a signal of lateral branching episodes, as well as their likely causes. Roughly, the idea is that lateral branching will create signature patterns of genealogical discordance, such that when these patterns are detected we can infer that certain kinds of lateral branching have likely occurred.

In this paper, I am interested in the philosophical implications of using genealogical discordance in this way, in particular for the philosophy of modeling. After reviewing the history and development of reticulate phylogenetic trees in section 2, and explaining the methods using genealogical discordance in section 3 . I will elaborate on implications of this practice within philosophy of modeling (section 4). I will argue for three related claims: First, these phylogenetic methods are not captured well by existing discussions of multiple model idealizations (cf. Wimsatt, 1987; Weisberg, 2007, 2013). Second, the idealizations involved in these methods contribute to the development of truer, de-idealized phylogenetic models in a different way than has been recognized in the philosophical literature on phylogenetics, because de-idealization in this case happens automatically rather than manually (cf. Velasco, 2012). And third, this contribution of idealization to the aims of phylogeneticists is unmediated by increased understanding (cf. Potochnik, 2017).

These claims contribute to the literature on philosophy of scientific models. Philosophers have long been interested in the utility of making false or idealizing assumptions, and I extend the role of idealization beyond what has hitherto been recognized.

\section{Phylogenetic Models}

This section will review some of the history of phylogenetic reconstructions, including especially the eventual recognition that phylogenetic trees might have a reticulate structure.

In around 1837, Charles Darwin drew a tree-shaped structure in a notebook, to symbolize the divergence of species (figure 1a). Darwin was not the first to conceptualize the history of life as 
a branching tree, but it did cohere with his theory of evolution to do so, and the tree structure gave him a model by which to explain how the extant diversity of life could have emerged from a common ancestor. Many other scholars picked up on the tree as a way to claim particular relationships between different taxa. For example, one from Hitchcock (1840) is shown in figure 1c and two from Haeckel 1866,1879 ) are in figures 1d and 1e. The tree which ultimately made it into the Origin of Species is in figure $1 \mathrm{~b}$.

For about one hundred years, such a tree-like structure was the primary way to conceive of the history of life on earth. Indeed, one prevalent thought was that agreement (convergence) between trees constructed using different taxa or different methods would have provided proof that the history of life had a tree-like structure, so many researchers went to work trying to develop these trees (Doolittle \& Brunet, 2016, p. 2). The problem is that we now know that the history of life did not have a tree-like structure, at least insofar as tree-like structures are strictly branching. Strictly-branching tree diagrams are those with branches that, once they diverge, can never meet again.

Lynn Margulis 1967 ; 1970) famously proposed that a few instances of endosymbiosis had occurred in the past, and had radically affected the sorts of biological structures which were possible. Endosymbiosis occurs when two organisms form a symbiotic relationship such that one of them resides within the other. This can result in the two organisms coming to seem more like a single, unified entity, perhaps even jointly becoming one biological individual. The most well-known and agreed-upon instances of endosymbiosis are that of eukaryotes with the mitochondria and chloroplasts, both originally free-living bacteria which now form essential organelles in many eukaryotic cells. (See figure $2 \mathrm{a}$ for one of her attempts to integrate endosymbiosis into the tree of life.)

Endosymbiosis implies that the tree of life would indeed have to have a reticulate structure, or one where branches can reconnect, and therefore one which is not strictly-branching. For example, in the case of mitochondrial endosymbiosis, the branch that mitochondria are on and the branch with their hosts merge to become a single lineage.

Margulis' idea was controversial, but it caught on in different academic circles to different degrees. For example, the diagram in Fox et al. (1980), shown in figure 2b, indicates authors' resistance to a high propensity of endosymbiosis, only allowing that it occurred in the uncontroversial 


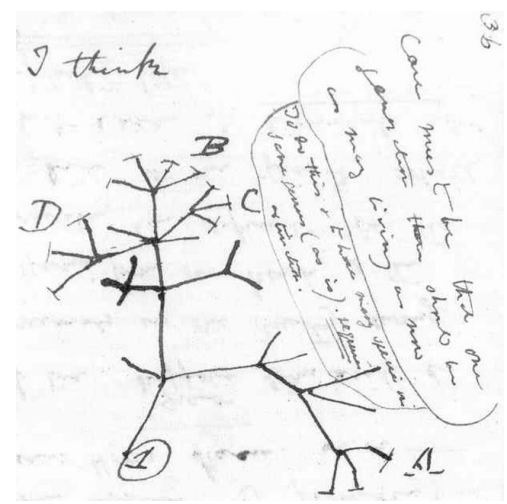

(a) Darwin (c. 1837)

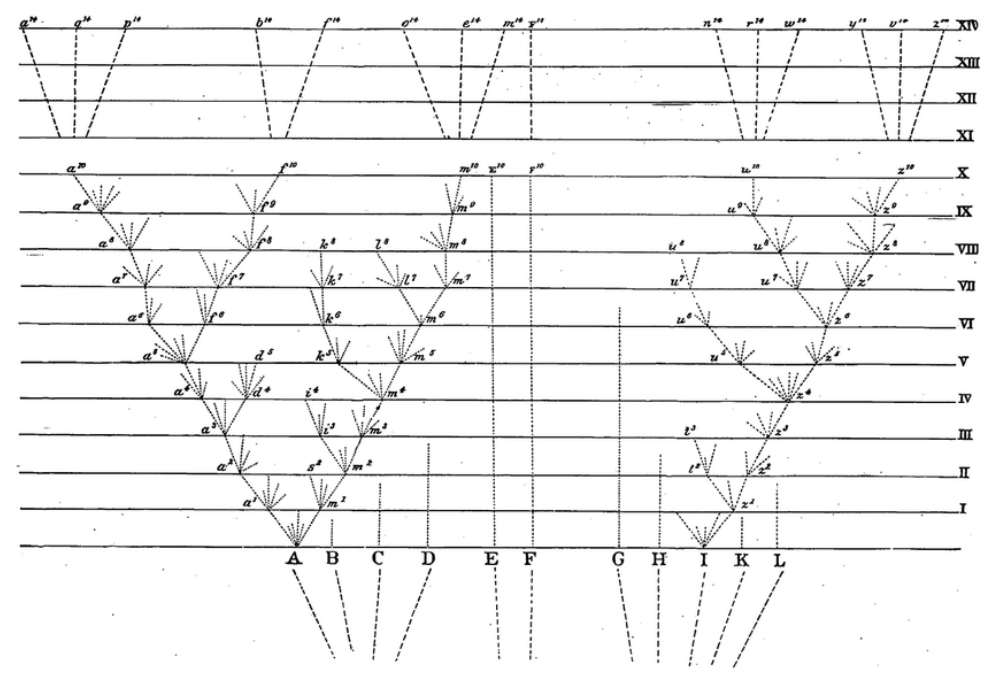

(b) Darwin (1859)

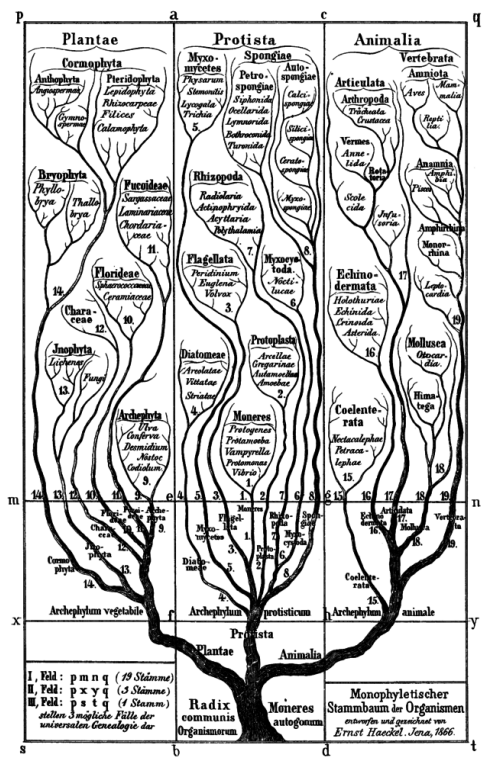

(d) Haeckel (1866)

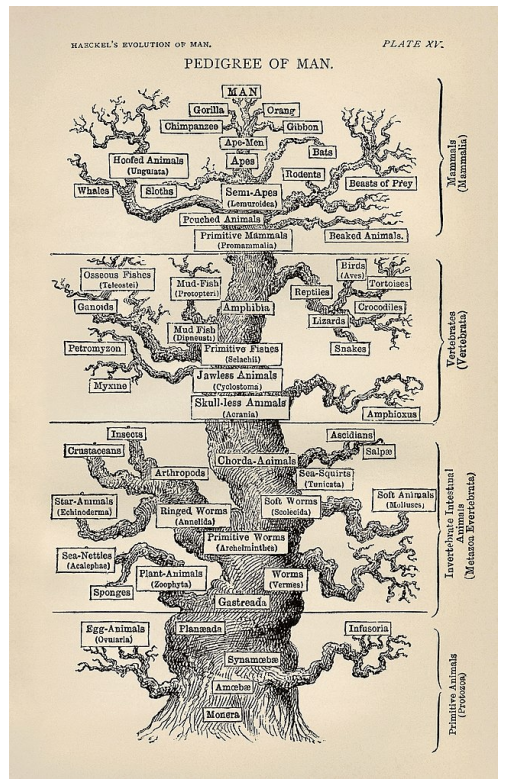

(e) Haeckel (1879)

(c) Hitchcock (1840); drawn by Orra White Hitchcock

Figure 1: Five examples of early strictly-branching trees. Figures (1a)-(1e) are all in the public domain. 
case of eukaryotic cell formation (and even then not really representing that as two reconnected branches on the tree). The diagram in Doolittle (1999), shown in figure 2c, by contrast, is maybe less precise but indicates openness to rampant endosymbiosis or perhaps other forms of branchmerging. Note that at around this same time biologists were beginning to understand how often different taxa of bacteria exchange genetic material horizontally.

Martin (1999) gives yet another slightly more precise version of a reticulated tree (figure 2d), allowing for many instances of reticulation but being a bit more specific about where they occurred. However, part of the text which accompanies the image says that this diagram "is not an answer to a question. It is a picture of a problem" (see Martin's caption to his fig. 2).

In brief, the problem is the standard algorithms we use to form phylogenetic trees, including cladistic or parsimony methods, maximum likelihood, and Bayesian methods. These standard algorithms all involve collecting a number of different characteristics of different taxa and comparing them, thereby making a tree that matches the data. Historically, and to some extent still today, some of the specifics of phylogenetic algorithms have been debated. Interest in phylogenetics among philosophers of science was piqued by Sober (1988), who laid out some of the main debates about phylogenetic methodology, some of which have continued (for example, regarding parsimony, see Felsenstein, 1978; Farris, 1983 but also more recently Huelsenbeck \& Lander, 2003; Kolaczkowski \& Thornton, 2004, Farris, 2008). For the purpose of this paper, the crucial fact is that the algorithms in general assume a strictly-branching structure, when we know that the history of life does not have such a structure.

This problem is even worse when we consider that endosymbiosis is not the only process that can generate lateral branches in a phylogenetic tree; such sources of reticulation are numerous and can affect all forms of life.

One primary source of reticulation in phylogenetic trees is lateral gene transfer. Lateral gene transfer occurs when the genes of one cell enter another cell and become part of the genome of the new cell. We know of three ways that this can happen: transformation, transduction, and conjugation (Ochman et al., 2000). In transformation, a recipient cell takes in genetic materials from its environment and starts using them to encode for proteins. In transduction, a virus called a bacteriophage transfers DNA to a recipient cell. And in conjugation, one cell implants its DNA 


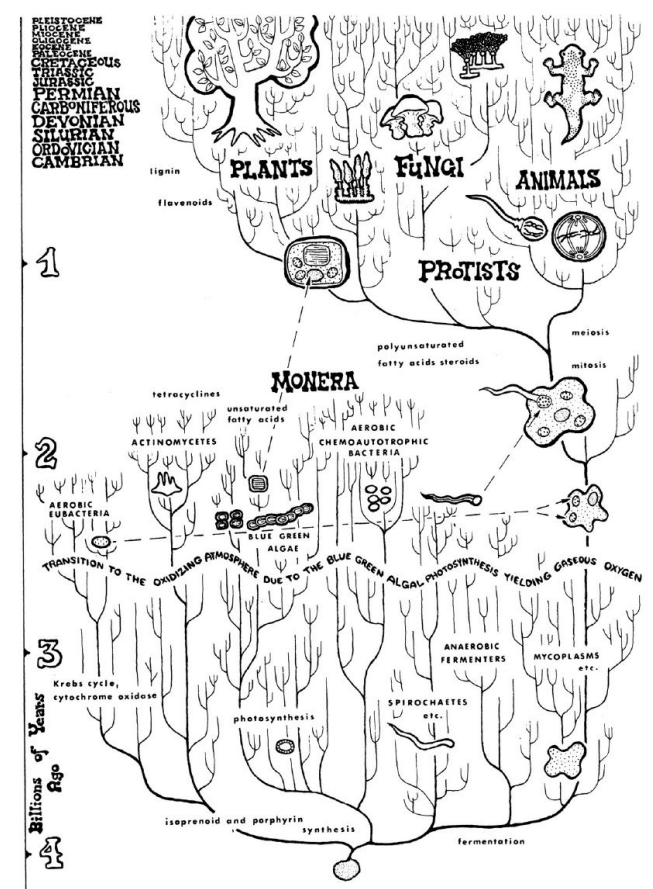

(a) Margulis (1970)

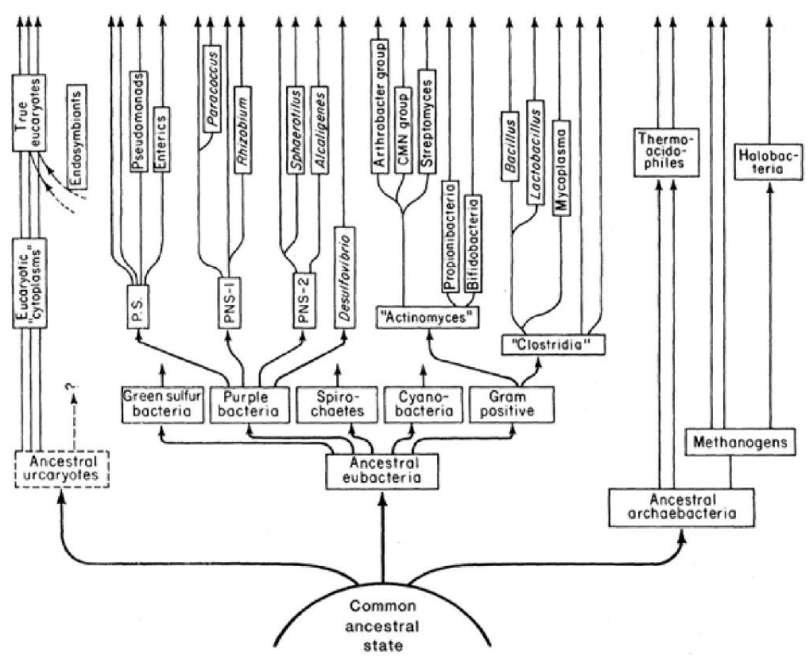

(b) Fox et al. (1980)

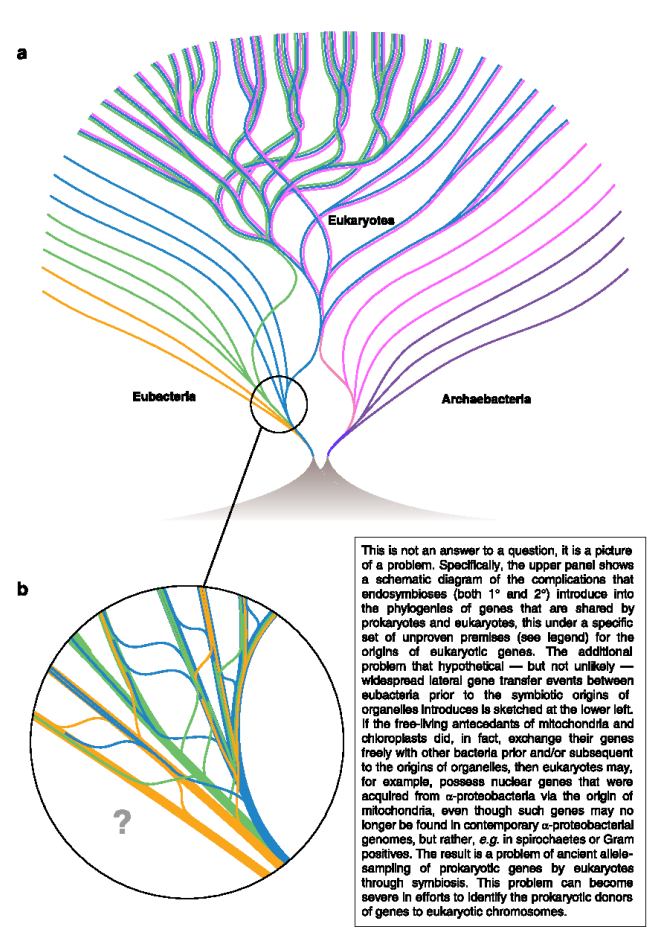

(d) Martin (1999)

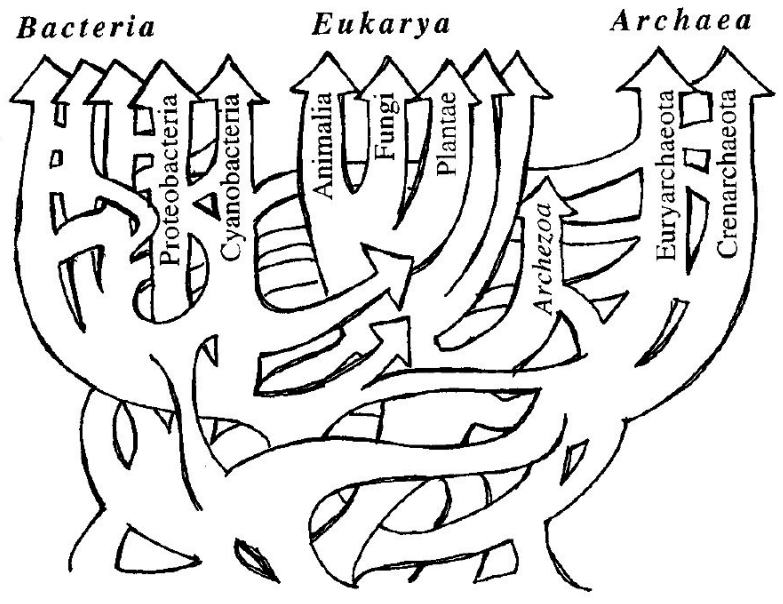

(c) Doolittle (1999)

Figure 2: Four examples of reticulated trees. Permission pending on figure reuse. 
into a recipient cell. We used to think that only microorganisms, in particular prokaryotic cells and viruses, could be involved in lateral gene transfer, but we now know that actually many prokaryotic bacteria can transfer their genes to eukaryotic cells, including those of large, multicellular organisms, especially via transduction (Hotopp et al., 2007). Lateral gene transfer will affect the rest of the cell line, whether somatic or germ line, including the potential for those genes to be inherited vertically between parents and offspring if the germ line cells have been affected. Primarily, though, lateral gene transfer occurs between bacteria and viruses; indeed, we now think that it happens with a relatively high frequency, and has been involved in several major evolutionary innovations Boucher et al. 2003; Zhaxybayeva \& Doolittle, 2011). The frequency of lateral gene transfer is one of the reasons why scientists have found it hard to come up with low-level taxonomic classification of bacteria (e.g., Ochman et al., 2005; Bapteste \& Boucher, 2008). For a further discussion of the implications of LGT for phylogenetics, see O'Malley (2014, p. 80-84, 101-108).

Another important source of reticulation is hybridization (including introgression), where members of two species produce offspring together.1 Often, hybridization happens between plants many plants can be cross-pollinated and then produce hybrids; this is often useful in an agricultural context (e.g., Whitney et al., 2010). However, hybridization happens in the animal kingdom as well - for example, grizzly bears and polar bears can reproduce together, a phenomenon which many predict will occur more often as the result of climate change, because the overlap between their ranges is expanding (e.g., Kutschera et al., 2014, Pongracz et al., 2017). If we do count hybridization as occurring between truly different species, then a population which resulted from hybridization may be represented by two branches on their phylogenetic tree merging back into one 2

\footnotetext{
${ }^{1}$ This is a little problematic for the biological species concept - I won't dwell on that here.

${ }^{2}$ There are other possible sources of reticulation, depending on the object of study, although these are unlikely to be analyzed using the same kinds of algorithms as LGT and hybridization. First, there are instances of endosymbiosis which do not initiate major biological transitions. The other - very common type of endosymbiosis occurs when a microorganism colonizes a larger organism as an obligate symbiont. For example, our microbiome is very important to our health (Dowd \& Renson, 2018). A lot of the taxa in our microbiome we inherited vertically (e.g., Moeller et al., 2018), but some of our microbiome we receive horizontally (e.g., Tung et al., 2015). These episodes of endosymbiosis wouldn't necessarily be registered in a tree of life, because most people still think that the taxa that make up our microbiome should be on different branches of the tree than we are. But, depending on how you conceive of a biological individual, for example, we may or may not contain our microbiome in just the same way as a eukaryotic cell contains its mitochondria (for discussion, see, e.g., Skillings, 2016, Doolittle \& Booth, 2017, O'Malley, 2014, p. 108117). It is therefore reasonable to include transfer of symbiotic microbes as one of the (possible) sources of
} 
The leading algorithms to determine evolutionary relationships, though, are not equipped to accommodate these sources of reticulation. However, lateral branching, whatever its cause, is common, and therefore cannot just be accommodated on a case-by-case basis. Insofar as the standard algorithms will necessarily exclude instances of reticulation, they seem ill-equipped to form an accurate diagram of the history of life. As Velasco (2012, p. 630) says $3^{3}$

If you don't bother looking for lateral events, you will build a tree that is capable of fitting the data and may not notice that anything has gone awry. Standard phylogenetic methods simply assume that the data is generated from a tree process and then find the best tree to fit the data... One simply cannot detect lateral events unless you specifically look for them. And there is no way of knowing ahead of time if you are working with a group where lateral events play an important causal and explanatory role.

One solution would be to create a new algorithm. Several replacements have been proposed, reticulation.

Second, reticulation may occur when subpopulations of the same species re-mix. For example, although the human species originated in a relatively small geographic area and then spread across the globe, it has recently come to light that this dispersion included many episodes of groups re-uniting and reproducing across group boundaries. So, if we were to construct an intraspecific human phylogeny, it would definitely have a reticulate structure (Hawks \& Cochran, 2006, Reich, 2018). This serves as good evidence that race is not biologically real - if biologically real races require isolated human populations, such a thing basically has never existed (cf. Andreasen, 2000). Humans apparently tend to meet up with one another and reproduce when they do so, meaning we need to replace our strictly-branching pictures of human evolution with "an interwoven plexus of genetic lineages that branch out and fuse once again with the passage of time" (Finlayson, 2013).

Third, cultural evolution may also provide another context in which reticulation is rampant, although it will not be very relevant to the focus of this paper. Many species acquire some of their characteristics from individuals other than their biological parents. Any sort of knowledge can be acquired elsewhere, along with many behavioral traits. Take language, for example: although your parents do help teach you language, they are certainly not the only ones. Probably you can think of words that you learned from someone other than your parents. That would be a case of horizontal inheritance, which would generate reticulation on a tree that represented the spread of language. One note here is that cultural inheritance has been used to show that some acquired characteristics can be inherited - for example, say I learn how to speak Spanish as an adult, and then I teach my children how to speak Spanish. They have now inherited that trait from me vertically, whereas I acquired it horizontally. Thus, the lines between horizontal and vertical inheritance can be blurred. (For a variety of cases of inheritance which complicate the dichotomy between horizontal and vertical inheritance, see Jablonka \& Lamb, 2005.) Furthermore, although humans may take special advantage of cultural inheritance, similar mechanisms apply in a range of other biological contexts, including transmission of birdsong (e.g., Aplin, 2019). For some recent philosophical discussions of cultural inheritance, see Sterelny (2012); Heyes (2018).

${ }^{3}$ Cf. Quinn (2016), who seems to think that phylogenetics involves considering all possible trees, when only all strictly-branching trees are considered. 
not all of which can be reviewed in detail here. For example, though, Velasco and Sober (2010) suggest one way to adjudicate between cases of independent evolution and cases of reticulation. Considerations of parsimony will often weigh in favor of independent evolution (reticulation requires adding another branch, thereby increasing the number of model components; although sometimes adding a branch will decrease the number of independent character changes needed to explain the data), whereas data fit might weigh in favor of reticulation, depending on the data. Velasco and Sober recommend use of the Akaike Information Criterion, which is a way to score the model taking into consideration both parsimony and data fit. This criterion will sometimes recommend trees with a reticulate structure, and sometimes will not.

Proponents of standard phylogenetic algorithms could, hypothetically, respond to proposals like this one by saying that they are not, in fact, purporting to give an actual tree of life - for instance, perhaps a phylogenetic tree does not purport to show historical relationships between taxa, but only relations of similarity and difference $4^{4}$ This argument is perhaps tenable as a response to the problems raised by reticulation: models should not be misunderstood to encapsulate phenomena that they were never meant to represent. Of course, in general, researchers do use trees as though they contain historical information. So, maintaining a distinction between phylogenetic trees and historically-oriented diagrams would come at the expense of abandoning this common use case.

In sum, then, there are several interrelated problems with current phylogenetic algorithms. First of all, many of these methods do not allow for lateral branching at all, despite the fact that we know that depicting the history of life often requires the use of a reticulate structure. Second, in order to apply existing methods for detecting various sources of reticulation, one often has to have good reason to believe in advance that such reticulation has occurred; indeed, some methods that do allow for lateral branching are not always able to accommodate the multiple sources of reticulation, such as endosymbiosis, LGT, and hybridization, so one may even have to know in advance which sources of reticulation are most likely in order to know what algorithms to apply to a given case. Third, restricting the scope of phylogenetic trees to showing only relationships of similarity and difference isn't a particularly helpful suggestion, because depictions of similarity and

\footnotetext{
${ }^{4}$ So-called "pattern cladists" used to go this route, although their views have fallen out of favor. See Williams and Ebach (2007) for a historical overview (although not an endorsement) of this position.
} 
difference are not necessarily depictions of historical relationships, and one of the main functions of phylogenetic trees within evolutionary biology is to test various hypotheses about the historical relationships between taxa. These three problems correspond to three questions philosophers and biologists may ask: (1) When are strictly-branching trees useful, and why? (2) How do we know whether to test for reticulation in a given case, before we have applied the algorithms that can detect it? and (3) What, exactly, should we take phylogenetic trees to represent?

In the next section, I will go into more detail on a particular method for detecting lateral branching events, one which relates to all of these questions. Then, I will argue that this method motivates an expansion of some accounts of the usefulness of idealization in model-based science (section 4).

\section{Genealogical Discordance}

Although genealogical discordance has received some attention from philosophers (see especially the special issue of Philosophy, Theory, and Practice in Biology edited by Haber and Molter), I will focus on the implications of genealogical discordance for philosophy of modeling, a topic which to my knowledge has not been discussed in the philosophical literature. To this end, I will first give an overview of genealogical discordance, and the ways in which it is used to study sources of reticulation. I will not be arguing in favor of using genealogical discordance to detect lateral episodes; rather, I think that the method is of philosophical interest, as will become clearer in section 4

Genealogical discordance occurs when different phylogenetic histories (e.g., gene trees) which are supposed to represent the same lineage of a particular biological entity (e.g., a species tree) disagree (Haber, 2019, p. 2). This can happen, for example, when trees formed on the basis of different genes within the same organisms or taxa show different branching relationships between these organisms or taxa. In other words, "lineages are leaky" (Haber, 2012, p. 612), so the tree at one hierarchical level (e.g., genes) may look different from the tree at another level (e.g., species). Horizontal exchange of genes, whether by LGT or some other means, can produce genealogical discordance. One early example of a paper which recognized this possibility is Brown and Doolittle 
(1997): "Horizontal gene transfer ... could result in a gene tree radically different from the species phylogeny" (p. 462). The authors used traditional phylogenetic methods on several different proteins, a process which produced many different trees. They then argued that LGT is a good explanation for the places in the models where the protein trees differed.

There is a lot to say about genealogical discordance from a philosophical perspective. For instance, there can be discordance within one level (i.e., different gene trees that are both supposed to represent the same species tree can disagree with one another), or between levels (i.e., gene trees can disagree with the species tree); this highlights that gene trees are imperfect proxies for species trees and complicates the matter of what our phylogenetic trees are of Haber, 2012, Maddison. 1997). However, I will focus on how researchers cope with discordance.

Genealogical discordance can be treated in roughly two different ways, what Haber (2019) calls resolution and reconciliation (p. 10), in response to Felsenstein (1988) saying, "Most of the interesting issues in phylogeneny reconstruction are in how to resolve these conflicts" (p. 524, emphasis added). Haber (following Nakhleh, 2013) says that resolution of genealogical discordance is not the only way to address it: reconciliation of genealogical discordance is also a possibility. I will discuss each of these approaches in turn 5

Historically, genealogical discordance was resolved by choosing an ultimate tree (say, of species) which was best supported by the set of individual trees (say, of genes). Degnan and Rosenberg (2006) summarize this approach: "In typical phylogenetic studies of individual genes, the estimated gene tree topology is used as the estimate of the species tree topology. When many loci are studied, the species tree topology is often estimated using the most frequently inferred gene tree topology" (p. 762; see also Maddison, 1997). For instance, if 100 gene histories for the taxa of interest are modeled and 95 of them agree on a particular topology, then that topology is presumed to be the most accurate representation of the relationships between the taxa, ignoring the gene histories for the five genes which discord with the dominant tree topology.

There are several problems with this approach. First, as the reader should by now be well aware, this standard approach to resolving discordance does not account for the various sources

\footnotetext{
${ }^{5}$ The distinction between resolution and reconciliation of genealogical discordance roughly corresponds to the distinction between concatenation and coalescence-based methods, respectively. For a historical overview, see Quinn (2019).
} 
of reticulation. Choosing the most likely strictly-branching tree from a set of discordant strictlybranching trees will never produce a tree with a reticulate structure. Second, though, this approach has theoretical problems even outside of the context of reticulation. Degnan and Rosenberg (2006) showed that, for trees with greater than five taxa (and, for some trees with four taxa), there will always be the possibility of "anomalous gene trees," or trees of genes which are more likely than the gene trees which match the actual species tree. Therefore, assuming that the species tree topology matches that of the most likely gene tree will be misleading $6^{6}$ These problems may lead one to be skeptical of the possibility of using discordant trees at all: for example, Doolittle (1999) wrote that if "different genes give different trees, and there is no fair way to suppress this disagreement, then a species (or phylum) can 'belong' to many genera (or kingdoms) at the same time: There really can be no universal phylogenetic tree of organisms based on such a reduction to genes" (p. 2128). Luckily, we are able to handle genealogical discordance without resorting to the genetic reductionism with which Doolittle was concerned.

Instead, one can "use the signal provided by discordant gene trees to infer species trees" Quinn, 2019 , p. 2). One possibility is that the fact of genealogical discordance - or, patterns thereof - can be useful in identifying sources of reticulation. As Baum (2007) and Degnan and Rosenberg (2009) point out, some of the reasons for genealogical discordance have to do with sources of reticulation. If a representative set of gene trees are used, for example, likely instances of lateral gene transfer will be evidenced by one "primary" history, one tree which applies to most of the genes, and one "minor" history, a tree which applies to only a small subset of genes, those which were subject to lateral transfer (Baum, 2007, p. 418); this inference is depicted in figures 3a. 3c. The primary gene history is taken to be equivalent to the species tree, with the exception of an LGT event that accommodates the minor gene history; the genes with the minor gene history are the ones which are laterally transferred, such that you can see the minor gene history "on top of" the primary gene history in figure $3 \mathrm{c}]^{7}$ Similarly, cases of hybridization will likely look like two "coprimary" histories, one history for each of the two hybridizing lineages, both with ample representation in the genome

6 Degnan et al. (2009) provide one solution to this problem, although it is outside of the context of reticulation and therefore not particularly relevant to the content of this paper.

${ }^{7}$ Note that this pattern may also appear for cases of endosymbiosis, if the minor history is specifically associated with the genome of an organelle such as the mitochondria, or perhaps with other obligate symbionts. 
A

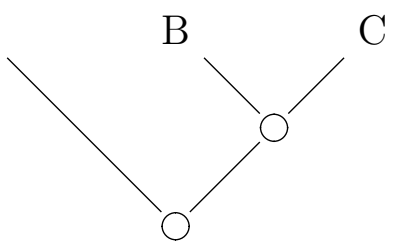

(a) Primary gene history

A

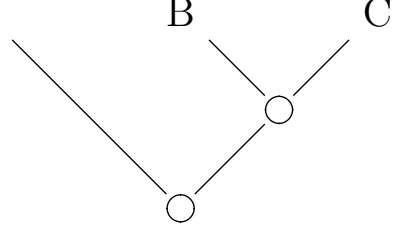

(d) Coprimary gene history
A

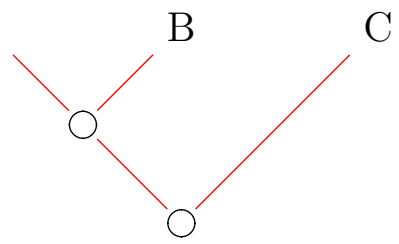

(b) Minor gene history

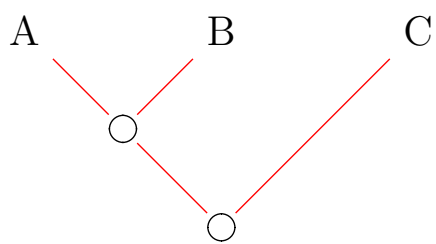

(e) Coprimary gene history

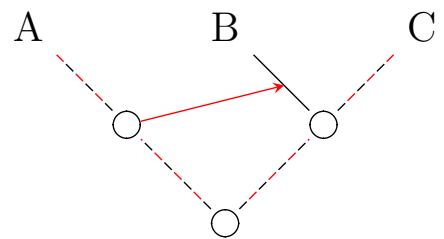

(c) Inferred LGT

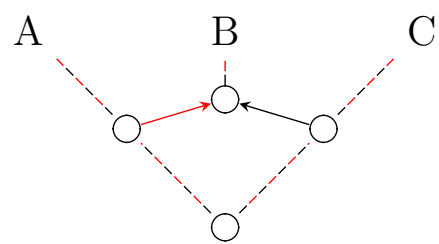

(f) Inferred hybridization

Figure 3: Examples of inferring sources of reticulation from genealogical discordance. In 3a.3c, an episode of lateral gene transfer is inferred from genealogical discordance where there is a primary gene history (3a) and a minor gene history (3b). In $3 \mathrm{~d}$, $3 \mathrm{f}$, an episode of hybridization is inferred on the basis of genealogical discordance where there are two distinct coprimary gene histories (3d and 3e). For related figures, see Maddison (1997); Degnan and Rosenberg (2006, 2009). In both 3c and 3f, the colors are used to show where the gene histories agree (dashed line with both colors) and where they disagree (solid color matching the relevant gene history), such that it is possible to see how the different gene histories "overlap" to form the inferred tree.

as a whole (Baum, 2007, p. 418); this inference is depicted in figures 3d 3f. Other than reticulation, patterns of genealogical discordance may indicate other episodes as well, such as incomplete lineage sorting (for discussion, see Haber, 2019). Any of these situations can be identified by contrast to other hypotheses, in this case that any genealogical discordance is the result of stochastic processes, i.e. random mutation. This brings us to Haber (2019)'s recommendation that discordant trees can also be reconciled, in some circumstances, rather than resolved. Reconciliation here involves recognizing that discordance between trees might be a "product of the underlying processes of lineage generation that can produce discordance" (p. 11). In other words, discordance might be evidence that the various processes which result in genealogical discordance have actually occurred. Sources of reticulation such as LGT and hybridization are some of these processes.

Reconciling genealogical discordance thus involves using two (or more) models which, by stipulation, do not allow for lateral branches to infer the presence of a lateral branch. In philosophy of modeling parlance, we might say that this is a case where two false models - false because of the idealizing assumption that no lateral branches ever occur - are used as a means to a truer claim. 
In other words, models which alone are inadequate for positing lateral events can be useful in combination towards this end. Note that the strictly-branching trees are not necessarily inadequate as gene trees, but are inadequate as species (or higher taxa) trees, so the transition between different types of trees is also important for this method. For further discussion of the hierarchical "nesting" (or lack thereof) of different types of trees or lineages, see Haber (2012); Neto (2019, 2020).

Let me now give two detailed examples of the reconciliation method in operation, both of which show that this method is a bit more complicated in practice than in principle. Singhal and Moritz (2012) found genealogical discordance between two species of Austrailian rainforest lizards. First, Singhal and Moritz used a standard algorithm (in this case, a Bayesian approach) to generate gene trees on a variety of nuclear and mitochondrial gene loci. There was more genealogical discordance between the mitochondrial genomes than the nuclear genomes. This is a pattern of discordance that indicates the possibility of a type of hybridization (namely, introgression), since the mitochondrial genes are inherited solely through the maternal line, effectively providing two co-primary gene histories. The researchers tested three each of two types of models for fit to these data: species trees with and without introgressive hybridization, i.e. a lateral branching event like that seen in figure [3f. The particular trees with introgression were chosen based on what was known about the area's biogeography, including possible historical opportunities for the related species to have interbred. The significant discordance between the nuclear and mitochondrial genes trees enabled the inference that a species tree which contained more mitochondrial gene flow between species was best supported by the data. The authors argue (with uncertainty, of course) that sex-specific processes best explain this particular pattern of introgression; because mitochondria are exclusively passed on through the maternal line, this indicates that the hybridization which occurred between the lineages under study was likely a matter of increased maternal gene flow from one lineage to another.

Morales-Briones et al. (2021) provide another recent example of the reconciliation method. Morales-Briones et al. were, again, using genealogical discordance between major and minor gene histories to detect an episode of hybridization, this time in the family Amaranthacaea s.1. MoralesBriones et al. used a maximum likelihood method to reconstruct the trees for 936 nuclear genes, a subset of which were informative for any given node. These gene trees allowed for the detection of 
discordance. The researchers found concordance indicating monophyly at the family level (agreement in 922 of 930 informative genes), but discordance at other significant nodes (e.g., only 231 out of 632 informative gene trees agreed on monophyly of the Chenopodiaceae subfamily). They identified five candidate hybridization events based on these different gene histories, depending on the maximum number of reticulations stipulated by the modelers. The researchers concluded that the best explanation for the patterns of discordance is a combination of introgression and incomplete lineage sorting (p. 229). Importantly, unlike Singhal and Moritz (2012), Morales-Briones et al. tested multiple hypotheses for lateral branching episodes, rather than just comparing one model with hybridization to a strictly-branching model, and the researchers recommend this strategy (over others, like network methods), especially in the case of ancient radiations. Morales-Briones et al. also call for more research on how to use genealogical discordance when multiple different sources of reticulation may be occurring in one clade; the methods outlined above do not offer any instruction on this more complex matter.

Before moving on, I would like to again emphasize that my focus on these methods involving genealogical discordance should not be taken to indicate my approval of use of these methods in all circumstances involving reticulation. For instance, there is a reason that this section has almost exclusively focused on hybridization and LGT: the methods discussed in this section are equipped to identify signals of hybridization and LGT, but other methods may be needed to identify other sources of reticulation, such as endosymbiosis. Additionally, there are other ways that reticulation episodes can be inferred, and it is outside the scope of this paper to explain and evaluate them all (for a review of other methods in the context of LGT, see Ragan, 2001). Algorithms and models alike are adequate for a research purpose (Parker, 2020), and I do not purport to be showing that a given method for tree construction is any better or worse than another. It may even be the case that the methods using genealogical discordance are eventually rejected entirely (for a discussion of some of the objections to these methods, see Quinn, 2019).

This section demonstrated that - sometimes - tree-shaped phylogenetic diagrams, formed using algorithms which do not allow lateral branching, can help us identify that lateral branching has in fact occurred. Genealogical discordance can, instead of being resolved by choosing the most likely of a set of trees, be reconciled by postulating that an event which would cause genealogical 
discordance in fact occurred. In general, this is a case where a set of models, each individually inadequate for identifying lateral branching events, are in combination able to identify them. The next section expands on this result, which has implications for views about the appropriate role of idealization in science.

\section{Implications: Purposes of Idealization}

In this section, I discuss implications of these methods for the role of idealization in modeling. In brief, I will argue that the methods using genealogical discordance illustrate a case where idealized or false models produce truer conclusions. However, I will suggest that this case is different from other accounts of the utility of idealizations in the philosophy of modeling literature. First, I will explain more thoroughly how it is that idealization operates in the reconciliation of genealogical discordance.

I claim that methods using genealogical discordance to infer reticulated phylogenetic trees involve a particular use of idealized models to produce truer conclusions. The idealized models, in this case, are the two or more strictly-branching trees (usually, gene trees) constructed using one of the standard algorithms for making trees (e.g., maximum likelihood methods). The relevant idealization is that these trees are required by the algorithms to be strictly branching. The gene trees themselves, as gene trees, are not idealized in this way; gene trees can be expected to be strictlybranching even when trees that represent relations between taxa like species cannot. But the gene trees as representations of species trees are idealized; in other words, we make an idealization when we assume that the species tree will, like the gene tree, be strictly-branching, an idealization that enables us to use gene trees to represent species trees. Even if it is not known in a particular case whether the assumption that the species tree is strictly-branching is a false assumption, it is an assumption held without regard for whether it is true, and is thus an idealization (Potochnik, 2017).

Of course, there are other idealizations involved in the construction of phylogenetic trees, even reticulated ones. For example, even in the methods involving reconciliation of genealogical discordance, there can sometimes be a conflation between gene trees and species trees, or at least 
an assumed relationship between gene trees and species trees that doesn't necessarily hold. Yet, systematists often use the simplifying assumption that gene trees are a good proxy for species trees, because what they have data on is genetic characteristics while what they are interested in is relationships among species or higher taxa. I do not dispute that the ultimate, reticulated trees resulting from reconciliation of genealogical discordance are still idealized, in this or other ways. But in order to maintain the assumption that gene trees are good proxies for species trees, it is necessary to remove the assumption that all trees are strictly-branching. It is this latter idealization on which this paper is focused.

How is the idealization involving strict branching used in the reconciliation of genealogical discordance? As I hope is clear on the basis of the discussion of these methods in section 3 , the construction of strictly-branching trees is a necessary step in these methods for the ultimate construction of a reticulated tree. Patterns of genealogical discordance - patterns of disagreement among strictly-branching trees - are the basis on which a reticulated tree is constructed. Evidence of genealogical discordance itself requires construction of the strictly-branching trees. Furthermore, this requirement is not imposed by anything like the psychological limitations of the researchers (which, as we will see shortly, is one reason for idealization often referred to in the literature). Rather, the algorithm that generates a potentially reticulated tree automatically combines information on multiple strictly-branching (idealized) trees in order to remove exactly this idealization.

I will now compare the use of idealization in this case to other uses of idealization in models, and show that the case of genealogical discordance does not easily fit into previously-recognized uses of idealization.

\subsection{Multi-model idealizations}

The method of reconciling genealogical discordance described above does not fit neatly into existing accounts of how multiple, idealized models are used in combination in science.

By far the most influential accounts of multiple-models idealization are Wimsatt (1987) and Weisberg (2007, 2013). Wimsatt (1987) notes a variety of ways in which combinations of multiple false models might be useful: (1) "to define the extremes of a continuum of cases in which the real case is presumed to lie," (2) "to look for results that are true in all of the models and therefore 
presumably independent of the various specific assumptions that vary from model to model" (this involves robustness testing, in which case "our truth is the intersection of independent lies," Levins, 1966, p. 423), (3) "to determine assumptions that are irrelevant to a given conclusion," and (4) "where a result is true in some models and false in others, to determine which assumptions or conditions a given result depends upon" (p. 31). Philosophers have especially focused on uses (2)(4), and there is now a burgeoning literature about robustness and the benefits of model agreement (e.g., Orzack \& Sober, 1993; Weisberg, 2006), in particular in the context of climate models (e.g., Lloyd, 2010, 2015; Parker, 2011, 2018; Winsberg, 2018; O’Loughlin, 2021).

However, the case of reconciling genealogical discordance discussed in section 3 does not match Wimsatt]'s discussion of the possible uses for multiple models. In the genealogical discordance case, the multiple models involved in producing an ultimately de-idealized model do not define the extremes of a continuum (it is hard to know what that would mean in the case of phylogenetics). Furthermore, they are not being used for robustness testing, meaning either looking for common ground between the models or looking for independence from or dependence on particular assumptions. Indeed, robustness testing in this case more closely matches the method of resolving genealogical discordance by picking the most frequent gene tree topology, i.e., looking at where the different models agree. By contrast, reconciling genealogical discordance involves taking model disagreement as a signal - not that there is something wrong with the models, such as that they have been based on faulty assumptions, but that there is something interesting such as LGT going on in the world.

Weisberg (2007, 2013) also discusses multiple-models idealization as one type of idealization (the other two types are minimalist idealization, where modelers attempt to only incorporate the core causal factors relevant to their study, and Galilean idealization, where idealizations are used temporarily but ultimately removed). Weisberg says that multiple-models idealization involves "building multiple related but incompatible models, each of which makes distinct claims about the nature and causal structure giving rise to a phenomenon" (Weisberg, 2007, p. 645; Weisberg, 2013. p. 103). Multiple-models idealization will not, according to Weisberg, result in the generation of a single best model. Multiple-models idealizations are often justified by tradeoffs between features of the different models. Often we use multiple models because features of the real world are too 
complex to be captured in a single, intelligible model.

However, Weisberg s multiple-models idealization fails to capture the idealization involved in reconciliation of genealogical discordance. First, reconciliation of genealogical discordance does, in fact, result in adoption of a single model (see figure 3). Second, there is no clear sense in which there are tradeoffs between features of the two discordant models, as both of them will have the same general features (although admittedly they will differ on the specifics). Finally, reconciling genealogical discordance is not a case where we are unable to capture the complexity of the world; surely, adding lateral branches to phylogenetic trees does increase their complexity, but not to a point of unintelligibility.

Thus the reconciliation of genealogical discordance is not adequately captured by either of these two influential accounts of the role of idealization in the use of multiple models. Neither Wimsatt nor Weisberg claim to provide exhaustive accounts of how idealization operates in multiple models, however, so the above should not be construed as a criticism of their accounts. Rather, it should be seen as an indication that the method of reconciling genealogical discordance expands the possibilities for the use of multiple-models idealization.

\subsection{De-Idealization}

In this section, I compare the case at hand to other accounts of the use of idealization in phylogenetics, especially Velasco (2012). I argue that the reconciliation of genealogical discordance is importantly different from these accounts insofar as the relevant idealization - that the original trees must be strictly branching - contributes to the formation of a de-idealized tree more automatically than manually. This is a distinction that has not been emphasized in the philosophical literature on models or idealization.

Velasco (2012) argues that tree thinking in biology (meaning: thinking about phylogenetic relationships as strictly-branching ones) is a useful practice, despite or even because of the idealizations involved. He suggests that if we see phylogenetic models as models, then we no longer require them to be entirely accurate; a strictly-branching model might be useful for us even if the real relationships between the taxa under consideration are not strictly-branching ones. For example, depending on the research question under investigation, we may simply be able to ignore any pos- 
sibility of lateral branches on the tree (Velasco considers this a case of "minimalist idealization," following Weisberg, 2007). However, as Velasco argues, this is often inadequate; for the reasons discussed in section 2, we may want to investigate sources of reticulation such as LGT or at least be able to figure out how often they occur. Velasco thus turns to a different kind of idealization used in phylogenetics: Galilean idealization. Galilean idealizations are introduced temporarily in order to improve clarity but are later removed (McMullin, 1985). As an example, Velasco discusses a method of identifying lateral branches that starts by constructing a strictly-branching tree and then looking for anomalous data that fail to fit that tree's structure, adding in lateral branches one by one to see if they improve fit to the data (Velasco \& Sober, 2010) 8

The method considered by Velasco is similar to the methods that rely on genealogical discordance, insofar as both start with strictly-branching trees and then end up with a reticulated tree (if the data suggest such a tree). Moreover, unlike in some cases of Galilean idealization, both Velasco and I are concerned with the role idealizations are playing in inferential processes, rather than with other motivations for idealization (e.g., computational tractability, comprehensibility). However, I do not think that Velasco's discussion adequately accounts for the way in which idealization is used in the case of reconciling genealogical discordance. In particular, I think that there is an important distinction to be drawn between the degree to which the de-idealization procedure must be performed manually by researchers and the degree to which the de-idealization procedure happens automatically, due to the nature of the algorithms being used.

De-idealization occurs manually when the idealizing assumption is, at some point, just removed by researchers. Galileo, for example, might begin an experiment by assuming that the Earth is flat, over a short distance. Once he has developed an adequate understanding using that (false) assumption, he can remove that assumption and adjust his analysis accordingly, without having to start from scratch. Velasco s case is also like this: we start with a strictly-branching tree, which provides us an imperfect but still useful representation of phylogenetic relationships. Then, we add a lateral branch - de-idealize, insofar as we are no longer prohibiting such branches - in order to see if this increases the performance of the model. This de-idealization step occurs manually because

\footnotetext{
${ }^{8}$ This perhaps fits under Wimsatt (1987)'s category: "An oversimplified model may act as a starting point in a series of models of increasing complexity and realism" (p. 30).
} 
the researcher makes a choice, at some stage, to remove the idealizing assumption that the tree has to be strictly branching. They can then use various algorithms to check whether a particular lateral branch improves the model with respect to the data. Of course, various automatic processes will play a role in these decisions as well - for example, in deciding which data count as "anomalous" so it is not as though the de-idealization procedure is wholly left to the researcher's discretion. But there is a clear stage in the process where the researcher has decided they have obtained enough information from the idealized, strictly-branching tree, at which point they are ready to test out different lateral branching events.

By contrast, I suggest, some de-idealization happens more automatically. By this I mean that the idealizations themselves are what produce the de-idealized result. This is clear in the case of reconciling genealogical discordance. In this case, we see that it is the original, multiple, idealized (i.e., strictly-branching) models that provide exactly the signal necessary to produce the de-idealized (i.e., potentially reticulate) model. For example, a primary gene history and a minor gene history together produce a tree with LGT, whereas two coprimary gene histories produce a tree with hybridization (see figure 3). Unlike in a case of more manual de-idealization, modelers do not at some point decide that they have enough information from the idealized models that they can "try out" a removal of the idealizing assumptions. Rather, models that incorporate these idealizing assumptions themselves produce a model that is de-idealized, in this case by means of an algorithm. Of course, researchers' decisions will still be relevant, even to automatic de-idealization; one must decide to even use the algorithms that reconcile genealogical discordance, for example, and must make decisions such as where the threshold lies between a minor gene history and a second coprimary gene history. The importance of judgment and expertise even in these more automatic de-idealization procedures is exemplified in the research performed by Morales-Briones et al. (2021), which involved using multiple different analyses to test a range of hypotheses to explain the observed discordance, a process which required considerable judgment on the part of the researchers.

Using this distinction, we can see that Velasco (2012) has provided an example where the assumption that phylogenetic trees are strictly branching is a Galilean idealization that can eventually be removed more-or-less manually, like many of the other cases of Galilean idealization discussed 
in the philosophy of modeling literature. Methods involving reconciliation of genealogical discordance, though, involve the automatic removal of the idealizing assumption that all trees must be strictly-branching. Both Velasco and I are interested in how the assumption that trees are strictlybranching can be removed, but the methods involved show that the assumption can be removed in different ways $9^{9}$ Like I argued in section 4.1 , then, the case of genealogical discordance methods provides an example of the uses of idealization not otherwise recognized in the relevant philosophical literature.

Should the reconciliation of genealogical discordance be seen as an instance of Galilean idealization? My discussion in section 4.1 perhaps indicates that reconciliation of genealogical discordance methods fall under the category of multiple-models idealization, which, under Weisberg (2007, 2013)'s framework, is contrasted with Galilean idealization (and minimalist idealization). The methods involved in reconciling genealogical discordance certainly (1) involve multiple models as a starting place, and also (2) involve de-idealization, as is characteristic of Galilean idealization. I admittedly don't see why we shouldn't say that these methods involve both multiple-models and Galilean idealization, perhaps contrary to Weisberg s taxonomy of idealization types.

Neto (2021) has also discussed the purposes of idealization in phylogenetics, although his account is more easily contrasted to mine and so can be handled briefly. Like me, Neto is interested in giving an example of the use of idealization in science not currently captured by other accounts of idealization, and he uses phylogenetics to do so. Neto however, focuses on the use of idealized models in "non-representational activities" in science. Specifically, Neto argues that idealized phylogenetic models contribute to disciplinary organization and collaboration. Neto focuses on the (false) assumption that lineages are completely isolated after splitting - false because, as we know, various sources of reticulation can cause tree branches to reconnect after they have split. However,

\footnotetext{
${ }^{9}$ There is another apparent distinction between the methods Velasco and I discuss. As noted above, gene trees are thought to be strictly branching, so the assumption that these trees are strictly branching is not objectionable in the way that the assumption that trees of taxa are strictly branching is objectionable. It thus appears that the initial assumption that the tree is strictly branching is an idealization in Velasco $\mathrm{s}$ case, whereas in my case, where the initial trees are gene trees, this assumption is not actually false at the beginning of the process. However, note that idealizations do not have to be false: they are assumptions held without regard for whether they are true or false. The assumption that trees are strictly branching is held without regard for whether it is true or false both in the algorithm Velasco examines and in the ones I examine. Thus, there is actually less difference between our accounts than one might think. Thanks to an anonymous referee for raising this point.
} 
idealized, strictly-branching trees can be useful to scientists, including in non-representational ways. For example, Neto argues that these trees can be useful in fostering collaboration between scientists by allowing them to combine their research to construct "supertrees," combinations of smaller phylogenetic trees. The combination of reticulated trees is much more difficult than the combination of strictly-branching trees, so the idealization is a crucial part of the practice of supertree construction.

I think that both Velasco (2012) and Neto (2021) have identified interesting and important ways in which idealization in phylogenetics - specifically, the idealization involved in requiring that trees be strictly-branching - contributes beneficially to scientific practice. However, I think that methods involving reconciliation of genealogical discordance, as elaborated in section 3 , demonstrate yet another way in which the idealizations involved in strictly-branching trees are useful ones: namely, that the combination of two (or more) strictly-branching trees can, on this methodology, more automatically produce a non-strictly branching tree, without the need for a researcher to take the step of manually removing the idealizing assumption from the model.

\subsection{Idealization and the Meso-Level Aims of Science}

Whether the methods reconciling genealogical discordance involve Galilean idealization or multiplemodels idealization (or both), these methods certainly are using the relevant idealization - that phylogenetic trees must be strictly-branching - as a means to developing a truer tree (a la Wimsatt, 1987). In this section, I will demonstrate how the case involving genealogical discordance differs from other accounts of how idealization serves the aims of science, largely as a function of the automatic de-idealization process explained in section 4.2 .

First, though, a review of the relevant literature on idealizations. It has long been recognized that models are only useful when they are, to some extent, false due to idealization. Cartwright (1983), for example, argues that, strictly speaking, all of our physical laws are only approximately true; she argues that idealizations can help our theories to explain phenomena, despite the observation that these theories "patently do not get the facts right" (p. 3). Furthermore, argues McMullin (1985), idealizations can help with the mathematical tractability of our models. Wimsatt 1987, 2007) enumerates a number of additional ways in which models can be false, but argues that at least 
some of these ways are consistent with productive use of these models. According to Wimsatt, false models have instrumental value in leading us to truer theories. False models can, for example, help us to understand more realistic models, or help to inspire research questions or hypotheses. All of the ways in which Wimsatt thinks that false models can be useful, though, are insofar as they help "in the search for better ones" (p. 30). Weisberg (2013) suggests that different types of idealization are incorporated or maintained in models for different reasons, depending on the purposes of the research (see especially chapter 6). For example, minimalist idealizations, which involves including only core causal factors involved in producing a phenomenon, are often best equipped to address research purposes which prioritize simplicity of explanation as a goal. Rancourt (2017) argues that false beliefs in general, but especially idealizations and approximations, can increase understanding.

Reutlinger, Hangleiter, and Hartmann (2018) argue for the usefulness of a particularly extreme case of idealization, that involved in "toy models." Toy models are highly idealized and simplified models, such as a model of a planet's orbit that consists of only the sun and that planet rather than other large bodies that also exert a gravitational force on that planet. Reutlinger et al. show that, while many cases of toy models provide mere how-possibly understanding of the phenomena they represent, other toy models can provide how-actually understanding. For our purposes, what is important is that they think that toy models facilitate either of these kinds of understanding because the idealization and simplification involved in these models affords researchers "epistemic access" to the phenomena (p. 1071). Thus, the reason for the idealization comes down to facts about what researchers are capable of grasping, i.e., psychological facts about human scientists.

Relatedly, there is a debate, primarily within the philosophy of physics, over whether certain idealizations are dispensable or essential to theory (see especially Shech, 2018, but also Shech, 2019; Fletcher et al., 2019, Strevens, 2019). Those who argue that idealizations are essential, such as Batterman (2002) and Bokulich (2008), among others, point to the ways in which our understanding of and explanations for certain phenomena (such as phase transitions) depend on idealizations. Bokulich has gone on to elaborate this view, explicating the ways in which fictions - idealizations incorporated into our models - are explanatory and thereby "vehicles for truth" (2016, p. 260).

Potochnik 2017, 2020) has recently proposed an even more expansive role for false models in 
science, and indeed for idealization in general. Potochnik starts with the two observations that the world is exceedingly complex and that our ability to learn about or understand such complexity is necessarily limited by our cognitive capacities. Idealization, Potochnik argues, helps to simplify the complexity inherent in the world in order to make it manageable for us to understand. This central role for idealization helps to explain why idealizations are found throughout scientific practice, and why scientists are usually not especially keen to de-idealize. The centrality of idealization also helps to show that, rather than the delimited and discrete roles for idealization offered by Wimsatt and Weisberg, there are instead many, interrelated motivations for idealization. Potochnik thinks that some of the reasons to idealize are temporary, in which case researchers will eventually seek to de-idealize, but that some of the reasons to idealize are permanent.

I am convinced that idealization can play all of the roles suggested by Cartwright, McMullin, Wimsatt, Elgin, Weisberg, Reutlinger et al., Bokulich, Potochnik, among others. Sometimes, idealization is useful because it is a step along the way to de-idealization; other times, idealization is useful because our limited cognitive capacities make it impossible for us to grasp the world in its full complexity. However, I think that the practice examined in section 3 indicates that these accounts need to be expanded, in particular with respect to multiple-models idealization.

Take Potochnik (2017, 2020)'s discussion of the relationship between idealization and the aims of science as exemplary. Recall Cartwright s insight that the theories which result from idealizations are not, strictly, true of the world. As Potochnik emphasizes, as soon as we admit that idealizations are central to the scientific enterprise, we need to explain why it is the case that untrue theories are by and large accepted as perfectly adequate by scientists and laypeople. Potochnik here draws on work that suggests that science does not aim exclusively at truth. For example, de Regt (2017, 2020) argues that understanding is a central aim of science (see, especially, chapter 2). de Regt persuasively defends a contextual account of understanding, where understanding mainly depends on intelligibility, and gives several examples from the history of physics to support his view. Potochnik, like de Regt, also focuses on the epistemic aim of understanding. If scientists are aiming at understanding rather than truth, we can make sense of the presence of "rampant" and "unchecked" idealizations in science (Potochnik, 2017, p. 57). Crucially, understanding is a goal which is both constrained by the world - our theories must be "true enough" (Elgin, 2004, 
2017) - but also by the cognitive abilities of those who are seeking to understand. Because the world is too complex for us to understand in its full complexity, we use idealizations as a tool to accomplish the aims of science. According to Potochnik, it is the falseness itself which contributes to understanding, by making the world more intelligible. She therefore provides a more direct route by which falseness of models or theories can serve the aims of science.

Along these lines, Rowbottom (2015, 2019) has argued that progress in science isn't necessarily linked to increased verisimilitude. Scientists might have other goals, such as increasing predictive power and increasing understanding, which are not always best facilitated by truthfulness, in part because of the usefulness of idealizations. As Rowbottom says, "Truth is sometimes stranger - more complex, more unaccommodating, less elegant, less comprehensible - than fiction" (2015, p. 101). Rowbottom's view accords with Potochnik's, insofar as both emphasize the downsides to trying to describe the world truly, in light of other possible aims of science, such as understanding.

A popular view, then, is something like the following: If we are trying to make sense of the fact that science often relies on false claims (idealizations), it helps to notice that science doesn't always aim at truth. When the aims of science are, for example, understanding (or prediction, policy guidance, etc.), it is easy to see how idealizations might contribute to these aims, for instance by making the complex world more intelligible to us. Perhaps we ultimately do use these idealizations and the resulting understanding to develop truer theories, but the primary aim of science isn't necessarily truth-related at all.

I wholeheartedly agree with this view, and think that it is often able to make sense of both the motivations for idealizing as well as the role idealizations play in our inferential processes. However, I think there is more to say. In particular, I think that it is useful to see how idealization serves lower-level, more specific aims of science, and whether these aims are truth-related. I argue that, in cases of automatic de-idealization, idealization may contribute to truth-related aims of science unmediated by a step that involves increased understanding.

Views such as Potochnik s that attempt to account for the role of idealization in science depend on the claim that the aim of science is not straightforwardly to just produce truer claims or more claims that are true. However, often these discussions of how idealization contributes to the aims of science fail to discriminate between more fine-grained goals that different researchers or research 
programs might have. One helpful distinction is provided by de Regt (2017, p. 90), who divides the aims of science into three levels: micro (individual scientists), meso (communities of scientists, for example, those working on the same set of research questions), and macro (all of science). Others have also argued that it doesn't ever make much sense to talk of the aims of science; for example, Rowbottom (2014) argues that it is more useful to distinguish finer-grained questions about scientific purposes (p. 1218-1219), in particular for discussions of realism/anti-realism. These finer grained distinctions between different aims of science have largely not been applied to the literature on the purposes of idealization. For example, although Potochnik (2017) readily admits that science has multiple aims (see chapter 3 and section 4.1.2, especially for examples of nonepistemic aims of science such as policy guidance), and indeed thinks that "whether a claim can help generate genuine understanding must depend also on the precise aim of the research" (p. 96), she nevertheless argues that "the epistemic aim of science is not truth but understanding" (p. 91). This claim, which she devotes all of chapter 4 to defending, involves (1) discussing the aims of science in monolithic terms, i.e., all of science has the same epistemic aim; (2) the use of the definite article "the" to pick out a single epistemic aim of science, and (3) putting understanding on a par with truth as a candidate aim of science. Each of these factors indicate that Potochnik is dealing with understanding as what de Regt would call a "macro" aim of science, and her discussion of idealization accordingly focuses on how idealizations can serve this aim 10

In the context of this paper, which is concerned with the contribution of idealizations to the production of potentially reticulated trees, it is not very useful to discuss "the aims of science" as though these were monolithic and context-independent. In the case of phylogenetics, the aim is something like "to depict historically accurate relationships among taxa," which, using de Regt's framework, is probably at most a meso-level aim. This aim is definitely truth-related; although, as Velasco (2012) and Neto (2021) note, we may use idealized (strictly-branching) trees for other purposes, like understanding or collaboration, phylogeneticists ultimately want an accurate historical representation.

How, then, do idealizations serve this aim? Certainly, this depends on the research context

\footnotetext{
${ }^{10}$ Of course, individual scientists or groups of scientists may also have understanding as an aim; understanding is not necessarily a macro-level aim. Nevertheless, Potochnik s discussion is largely confined to understanding as a macro-level aim.
} 
and the phylogenetic algorithms used. Sometimes, this might proceed according to views such as Potochniks, whereby we start with an idealized tree, this tree increases our understanding, and that greater understanding allows us to de-idealize. Such de-idealization will likely be "manual," according to the manual/automatic distinction introduced in section 4.2, For example, a researcher using the method that Velasco (2012) discusses may, as a result of making a strictly-branching tree, have an increased understanding of the approximate historical relationships that hold between the relevant taxa, the sorts of anomalous data to look for in checking for lateral branching episodes, and more. We could perhaps concoct a case in which the idealized, strictly-branching tree did not produce any increased understanding - perhaps the researcher already knew all of the information that this tree provided on the basis of past research, for instance, or the modeler is siloed from the overall research project in such a way as to not know which taxa are being examined. But it is intuitive to see how producing a strictly-branching tree first would produce understanding which could be instrumental (if not necessary) for the de-idealization procedure Velasco outlines.

The methods involving genealogical discordance reviewed in section 3 certainly need not involve de-idealization by means of increased understanding. In Velasco's case, the researcher does have to have access to the idealized, strictly-branching trees as a starting point, after which the lateral branches are added manually in the de-idealization process. In the case of methods reconciling genealogical discordance, the fact that the de-idealization is carried out more automatically means that, in principle, the researchers do not have to ever see the strictly-branching trees, and can just be presented with candidate reticulated trees at the end. (In practice, researchers have many other reasons to want to see the strictly-branching trees - including their contribution to understanding! - but the algorithms do not require this.) Thus, idealization in the case of phylogenetic trees is able to contribute to the construction of more accurate, de-idealized trees by means unmediated by a stage of increased understanding.

In more general terms, then, we have a truth-related, meso-level aim of science that is served by idealization without the idealization (necessarily) leading to increased understanding. This is distinct from the role for idealization in views such as Potochnik (2017)'s insofar as it (1) focuses on a meso-level, rather than macro-level, aim and (2) involves idealization contributing to a truthrelated aim without relying on other aims (such as understanding) to mediate that contribution. 


\section{$5 \quad$ Recap and Conclusion}

Phylogenetics has interested philosophers of biology for some time. One lingering debate within phylogenetics, on which some philosophers have weighed in, concerns how to best model lateral branching episodes. Lateral branches may occur for a variety of reasons, including endosymbiosis but also lateral gene transfer and hybridization, among others. However, the predominant algorithms that researchers use for drawing phylogenetic trees rules out lateral branches by fiat. How or whether to update phylogenetic algorithms is a subject of continuing debate.

One approach, involving inferences made on the basis of patterns of genealogical discordance, is especially interesting for philosophical debates about modeling. This method uses multiple models generated by standard phylogenetic algorithms, each of which necessarily does not contain any lateral branches, to infer the presence and location of lateral branches, as well as the most likely source of reticulation at work. In general terms, this is a case of taking multiple false or inadequate models and combining them to reach a truer conclusion.

I have argued that an examination of this method of reconciling genealogical discordance has implications for philosophy of modeling. First, this scientific practice is not adequately captured by existing accounts of multiple-models idealization, which focus mostly on the use of multiple models for robustness testing. Second, the resulting model (potentially one with lateral branches) is produced by automatically rather than manually de-idealizing from the idealized models, i.e., removing the assumption that the trees must be strictly branching. This distinction is not captured in other accounts of the purposes of idealization in phylogenetics. Third, in virtue of the features of the automatic de-idealization process, I have argued that the reconciliation of genealogical discordance involves idealization in service of a meso-level aim of science not necessarily mediated by increased understanding on the part of the researchers, a use of idealization that has gone unrecognized in accounts of how idealization serves the macro-level aims of science.

These lessons apply to the case of reconciliation of genealogical discordance, but I suspect that they also hold in other cases unrelated to phylogenetics, especially relating to meso-level scientific aims. Other researchers should examine additional modeling contexts in order to continue to progress at identifying the purposes of idealization. A further area in need of work in the context 
of phylogenetics and otherwise has to do with model evaluation. I am sympathetic to the view that different models are more or less fit for different research contexts. It is an ongoing project to delineate which phylogenetic models or algorithms are best suited to which contexts, and why. I thus encourage others to continue to extend the role of idealization in science, and to consider how we can evaluate the different uses of different idealizations relative to the purposes at hand.

\section{Acknowledgements}

This paper greatly benefited from feedback by Alisa Bokulich, Matt Haber, and Celso Neto, as well as the attendees at POBAMz (2020) and SURe (2021). This material is based upon work supported by the National Science Foundation Graduate Research Fellowship Program under Grant No. DGE1840990. Any opinions, findings, and conclusions or recommendations expressed in this material are those of the author and do not necessarily reflect the views of the National Science Foundation. 


\section{References}

Andreasen, R. O. (2000). Race: Biological Reality or Social Construct? Philosophy of Science, 67, S653-S666. doi: 10.1086/392853

Aplin, L. M. (2019). Culture and cultural evolution in birds: a review of the evidence. Animal Behaviour, 147, 179-187. doi: 10.1016/j.anbehav.2018.05.001

Bapteste, E., \& Boucher, Y. (2008). Lateral gene transfer challenges principles of microbial systematics. Trends in Microbiology, 16(5), 200-207. doi: 10.1016/j.tim.2008.02.005

Batterman, R. W. (2002). The Devil in the Details: Asymptotic Reasoning in Explanation, Reduction, and Emergence. Oxford University Press.

Baum, D. A. (2007). Concordance trees, concordance factors, and the exploration of reticulate genealogy. TAXON, 56(2), 417-426. doi: 10.1002/tax.562013

Bokulich, A. (2008). Reexamining the Quantum-Classical Relation: Beyond Reductionism and Pluralism. Cambridge University Press.

Bokulich, A. (2009). Explanatory Fictions. In M. Suarez (Ed.), Fictions in Science: Philosophical Essays on Modeling and Idealization (p. 21). Routledge.

Bokulich, A. (2016). Fiction As a Vehicle for Truth: Moving Beyond the Ontic Conception. The Monist, $99(3)$, 260-279. doi: 10.1093/monist/onw004

Boucher, Y., Douady, C. J., Papke, R. T., Walsh, D. A., Boudreau, M. E. R., Nesbø, C. L., ... Doolittle, W. F. (2003). Lateral Gene Transfer and the Origins of Prokaryotic Groups. Annual Review of Genetics, 37(1), 283-328. doi: 10.1146/annurev.genet.37 .050503 .084247

Brown, J. R., \& Doolittle, W. F. (1997). Archaea and the prokaryote-to-eukaryote transition. Microbiology and molecular biology reviews : MMBR, 61(4), 456-502. doi: 10.1128/ $.61 .4 .456-502.1997$

Cartwright, N. (1983). How the Laws of Physics Lie. Oxford : New York: Oxford University Press.

Darwin, C. (1837). Notebook B: Transmutation of species (1837-1838). Retrieved 2020-12- 
02, from http://darwin-online.org.uk/content/frameset?itemID=CUL-DAR121. -\&viewtype=text\&pageseq=1

Darwin, C. (1859). The origin of species: by means of natural selection, or, The preservation of favored races in the struggle for life. New York: Signet.

Degnan, J. H., DeGiorgio, M., Bryant, D., \& Rosenberg, N. A. (2009). Properties of Consensus Methods for Inferring Species Trees from Gene Trees. Systematic Biology, 58(1), 35-54. doi: 10.1093/sysbio/syp008

Degnan, J. H., \& Rosenberg, N. A. (2006). Discordance of Species Trees with Their Most Likely Gene Trees. PLoS Genetics, 2(5), e68. doi: 10.1371/journal.pgen.0020068

Degnan, J. H., \& Rosenberg, N. A. (2009). Gene tree discordance, phylogenetic inference and the multispecies coalescent. Trends in Ecology $\&$ Evolution, 24(6), 332-340. doi: 10.1016/j.tree.2009.01.009

de Regt, H. W. (2017). Understanding scientific understanding. New York: Oxford University Press.

de Regt, H. W. (2020). Understanding, Values, and the Aims of Science. Philosophy of Science, 87(5), 921-932. doi: 10.1086/710520

Doolittle, W. F. (1999). Phylogenetic Classification and the Universal Tree. Science, 284(5423), 2124-2128. doi: 10.1126/science.284.5423.2124

Doolittle, W. F., \& Booth, A. (2017). It's the song, not the singer: an exploration of holobiosis and evolutionary theory. Biology \& Philosophy, 32(1), 5-24. doi: 10.1007/ s10539-016-9542-2

Doolittle, W. F., \& Brunet, T. D. P. (2016). What Is the Tree of Life? PLOS Genetics, 12(4), e1005912. doi: 10.1371/journal.pgen.1005912

Dowd, J. B., \& Renson, A. (2018). "Under the Skin" and into the Gut: Social Epidemiology of the Microbiome. Current Epidemiology Reports, 5(4), 432-441. doi: 10.1007/ s40471-018-0167-7

Elgin, C. Z. (2004). True Enough. Philosophical Issues, 14(1), 113-131. doi: 10.1111/ 
j.1533-6077.2004.00023.x

Elgin, C. Z. (2017). True Enough. MIT Press.

Farris, J. S. (1983). The logical basis of phylogenetic analysis. In N. I. Platnick \& V. A. Funk (Eds.), Advances in cladistics (Vol. II, pp. 7-36). New York, NY: Columbia University Press.

Farris, J. S. (2008). Parsimony and explanatory power. Cladistics, 24(5), 825-847. doi: https://doi.org/10.1111/j.1096-0031.2008.00214.x

Felsenstein, J. (1978). Cases in which Parsimony or Compatibility Methods Will be Positively Misleading. Systematic Zoology, 27(4), 401-410. doi: 10.2307/2412923

Felsenstein, J. (1988). Phylogenies from Molecular Sequences: Inference and Reliability. Annual Review of Genetics, 22, 521-565.

Finlayson, C. (2013). Viewpoint: Human evolution, from tree to braid. BBC News.

Fletcher, S. C., Palacios, P., Ruetsche, L., \& Shech, E. (2019). Infinite idealizations in science: an introduction. Synthese, 196(5), 1657-1669. doi: 10.1007/s11229-018-02069-6

Fox, G. E., Stackebrandt, E., Hespell, R. B., Gibson, J., Maniloff, J., Dyer, T. A., ... Woese, C. R. (1980). The phylogeny of prokaryotes. Science, 209(4455), 457-463. doi: 10.1126/science. 6771870

Haber, M. H. (2012). Multilevel Lineages and Multidimensional Trees: The Levels of Lineage and Phylogeny Reconstruction. Philosophy of Science, 79(5), 609-623. doi: $10.1086 / 667849$

Haber, M. H. (2019). Species in the Age of Discordance. Philosophy, Theory, and Practice in Biology, 11 (20200624). doi: 10.3998/ptpbio.16039257.0011.021

Haber, M. H., \& Molter, D. J. (2019). Species in the Age of Discordance: Meeting Report and Introduction. Philosophy, Theory, and Practice in Biology, 11. doi: 10.3998/ ptpbio.16039257.0011.012

Haeckel, E. (1866). Generelle morphologie der organismen. Allgemeine grundzüge der organischen formen-wissenschaft, mechanisch begründet durch die von Charles Dar- 
win reformirte descendenztheorie. Berlin: G. Reimer. (Pages: 1-626) doi: 10.5962/ bhl.title.3953

Haeckel, E. (1879). The Evolution of Man: A Popular Exposition of the Principal Points of Human Ontogeny and Phylogeny. Appleton.

Hawks, J., \& Cochran, G. (2006). Dynamics of Adaptive Introgression from Archaic to Modern Humans. PaleoAnthropology, 101-115.

Heyes, C. M. (2018). Cognitive gadgets: the cultural evolution of thinking. Cambridge, Massachusetts: The Belknap Press of Harvard University Press.

Hitchcock, E. (1840). Elementary Geology. Ivison \& Phinney.

Hotopp, J. C. D., Clark, M. E., Oliveira, D. C. S. G., Foster, J. M., Fischer, P., Torres, M. C. M., ... Werren, J. H. (2007). Widespread Lateral Gene Transfer from Intracellular Bacteria to Multicellular Eukaryotes. Science, 317(5845), 1753-1756. doi: 10.1126/science. 1142490

Huelsenbeck, J. P., \& Lander, K. M. (2003). Frequent Inconsistency of Parsimony Under a Simple Model of Cladogenesis. Systematic Biology, 52(5), 641-648. doi: 10.1080/ 10635150390235467

Jablonka, E., \& Lamb, M. J. (2005). Evolution in Four Dimensions: Genetic, Epigenetic, Behavioral, and Symbolic Variation in the History of Life. MIT Press.

Kolaczkowski, B., \& Thornton, J. W. (2004). Performance of maximum parsimony and likelihood phylogenetics when evolution is heterogeneous. Nature, 431(7011), 980984. doi: 10.1038/nature02917

Kutschera, V. E., Bidon, T., Hailer, F., Rodi, J. L., Fain, S. R., \& Janke, A. (2014). Bears in a Forest of Gene Trees: Phylogenetic Inference Is Complicated by Incomplete Lineage Sorting and Gene Flow. Molecular Biology and Evolution, 31(8), 2004-2017. doi: $10.1093 / \mathrm{molbev} / \mathrm{msu} 186$

Levins, R. (1966). The strategy of model building in population biology. American Scientist, 54(4), 421-431. (Publisher: Sigma Xi, The Scientific Research Society) 
Lloyd, E. A. (2010). Confirmation and Robustness of Climate Models. Philosophy of Science, 777(5), 971-984. doi: 10.1086/657427

Lloyd, E. A. (2015). Model robustness as a confirmatory virtue: The case of climate science. Studies in History and Philosophy of Science Part A, 49, 58-68. doi: 10.1016/ j.shpsa.2014.12.002

Maddison, W. P. (1997). Gene Trees in Species Trees. Systematic Biology, 46(3), 523-536. doi: $10.1093 /$ sysbio/46.3.523

Margulis, L. (1970). Origin of Eukaryotic Cells: Evidence and Research Implications for a Theory of the Origin and Evolution of Microbial, Plant, and Animal Cells on the Precambrian Earth. Yale University Press.

Martin, W. (1999). Mosaic bacterial chromosomes: a challenge en route to a tree of genomes. BioEssays, 21(2), 99-104. doi: https://doi.org/10.1002/(SICI)1521-1878(199902)21: 2〈99::AID-BIES3 $\rangle$ 3.0.CO;2-B

McMullin, E. (1985). Galilean idealization. Studies in History and Philosophy of Science Part A, 16(3), 247-273. doi: 10.1016/0039-3681(85)90003-2

Moeller, A. H., Suzuki, T. A., Phifer-Rixey, M., \& Nachman, M. W. (2018). Transmission modes of the mammalian gut microbiota. Science, 362(6413), 453-457. doi: 10.1126/ science.aat 7164

Morales-Briones, D. F., Kadereit, G., Tefarikis, D. T., Moore, M. J., Smith, S. A., Brockington, S. F., .. Yang, Y. (2021). Disentangling Sources of Gene Tree Discordance in Phylogenomic Data Sets: Testing Ancient Hybridizations in Amaranthaceae s.l. Systematic Biology, 70(2), 219-235. doi: 10.1093/sysbio/syaa066

Nakhleh, L. (2013). Computational approaches to species phylogeny inference and gene tree reconciliation. Trends in Ecology E Evolution, 28(12), 719-728. doi: 10.1016/ j.tree.2013.09.004

Neto, C. (2019). What Is a Lineage? Philosophy of Science, 86(5), 1099-1110. (Publisher: The University of Chicago Press) doi: 10.1086/705511 
Neto, C. (2020). When imprecision is a good thing, or how imprecise concepts facilitate integration in biology. Biology \& Philosophy, 35(6), 58. doi: 10.1007/s10539-020-09774 $-\mathrm{y}$

Neto, C. (2021). From idealizations to social practices in science: the case of phylogenetic trees. Synthese. doi: 10.1007/s11229-021-03271-9

Ochman, H., Lawrence, J. G., \& Groisman, E. A. (2000). Lateral gene transfer and the nature of bacterial innovation. Nature, 405(6784), 299-304. doi: 10.1038/35012500

Ochman, H., Lerat, E., \& Daubin, V. (2005). Examining bacterial species under the specter of gene transfer and exchange. Proceedings of the National Academy of Sciences, 102(suppl 1), 6595-6599. doi: 10.1073/pnas.0502035102

O’Malley, M. A. (2014). Philosophy of microbiology. Cambridge, United Kingdom: Cambridge University Press.

Orzack, S. H., \& Sober, E. (1993). A Critical Assessment of Levins's The Strategy of Model Building in Population Biology (1966). The Quarterly Review of Biology, 68(4), 533546. (Publisher: University of Chicago Press)

O'Loughlin, R. (2021). Robustness reasoning in climate model comparisons. Studies in History and Philosophy of Science Part A, 85, 34-43. doi: 10.1016/j.shpsa.2020.12 .005

Parker, W. S. (2011). When Climate Models Agree: The Significance of Robust Model Predictions. Philosophy of Science, 78(4), 579-600. doi: 10.1086/661566

Parker, W. S. (2018). The Significance of Robust Climate Projections. In E. A. Lloyd \& E. Winsberg (Eds.), Climate Modelling (pp. 273-296). Springer International Publishing. doi: 10.1007/978-3-319-65058-6_9

Parker, W. S. (2020). Model Evaluation: An Adequacy-for-Purpose View. Philosophy of Science, 87(3), 457-477. doi: 10.1086/708691

Pongracz, J. D., Paetkau, D., Branigan, M., \& Richardson, E. (2017). Recent Hybridization between a Polar Bear and Grizzly Bears in the Canadian Arctic. Arctic, 70(2), 151- 
160.

Potochnik, A. (2017). Idealization and the Aims of Science. Chicago, IL: University of Chicago Press.

Potochnik, A. (2020). Idealization and Many Aims. Philosophy of Science. doi: 10.1086/ 710622

Quinn, A. (2016). Phylogenetic inference to the best explanation and the bad lot argument. Synthese, 193(9), 3025-3039. doi: 10.1007/s11229-015-0908-9

Quinn, A. (2019). Diagnosing discordance: signal in data, conflict in paradigms. Philosophy, Theory, and Practice in Biology, 11(20200624). doi: 10.3998/ptpbio.16039257.0011 .017

Ragan, M. A. (2001). Detection of lateral gene transfer among microbial genomes. Current Opinion in Genetics \&6 Development, 11(6), 620-626. doi: 10.1016/S0959-437X(00) 00244-6

Rancourt, B. T. (2017). Better Understanding Through Falsehood. Pacific Philosophical Quarterly, 98(3), 382-405. doi: 10.1111/papq.12134

Reich, D. (2018). Who we are and how we got here: ancient DNA and the new science of the human past. New York: Pantheon Books.

Reutlinger, A., Hangleiter, D., \& Hartmann, S. (2018). Understanding (with) Toy Models. The British Journal for the Philosophy of Science, 69(4), 1069-1099. doi: 10.1093/ bjps/axx005

Rowbottom, D. P. (2014). Aimless science. Synthese, 191(6), 1211-1221. doi: 10.1007/ s11229-013-0319-8

Rowbottom, D. P. (2015). Scientific progress without increasing verisimilitude: In response to Niiniluoto. Studies in History and Philosophy of Science Part A, 51, 100-104. doi: 10.1016/j.shpsa.2015.01.003

Rowbottom, D. P. (2019). The Instrument of Science: Scientific Anti-Realism Revitalised. Routledge. 
Sagan, L. (1967). On the Origin of Mitosing Cells. Journal of Theoretical Biology, 14, $225-274$.

Shech, E. (2018). Infinite idealizations in physics. Philosophy Compass, 13(9), e12514. doi: https://doi.org/10.1111/phc3.12514

Shech, E. (2019). Infinitesimal idealization, easy road nominalism, and fractional quantum statistics. Synthese, 196(5), 1963-1990. doi: 10.1007/s11229-018-1680-4

Singhal, S., \& Moritz, C. (2012). Testing hypotheses for genealogical discordance in a rainforest lizard. Molecular Ecology, 21(20), 5059-5072. doi: 10.1111/j.1365-294X $.2012 .05747 . \mathrm{x}$

Skillings, D. (2016). Holobionts and the ecology of organisms: Multi-species communities or integrated individuals? Biology \& Philosophy, 31(6), 875-892. doi: 10.1007/ s10539-016-9544-0

Sober, E. (1988). Reconstructing the past: parsimony, evolution, and inference. Cambridge, MA: MIT Press.

Sterelny, K. (2012). The evolved apprentice: how evolution made humans unique. Cambridge: The MIT Press.

Strevens, M. (2019). The structure of asymptotic idealization. Synthese, 196(5), 1713-1731. doi: $10.1007 / \mathrm{s} 11229-017-1646-\mathrm{y}$

Tung, J., Barreiro, L. B., Burns, M. B., Grenier, J.-C., Lynch, J., Grieneisen, L. E., ... Archie, E. A. (2015). Social networks predict gut microbiome composition in wild baboons. eLife, 4. doi: 10.7554/eLife.05224

Velasco, J. D. (2012). The Future of Systematics: Tree Thinking without the Tree. Philosophy of Science, $79(5), 624-636$. doi: 10.1086/667878

Velasco, J. D., \& Sober, E. (2010). Testing for treeness: lateral gene transfer, phylogenetic inference, and model selection. Biology \& Philosophy, 25(4), 675-687. doi: 10.1007/ s10539-010-9222-6

Weisberg, M. (2006). Robustness Analysis. Philosophy of Science, 73, 730-742. 
Weisberg, M. (2007). Three Kinds of Idealization:. Journal of Philosophy, 104(12), 639-659. doi: 10.5840/jphil20071041240

Weisberg, M. (2013). Simulation and similarity: using models to understand the world. Oxford: Oxford University Press.

Whitney, K. D., Ahern, J. R., Campbell, L. G., Albert, L. P., \& King, M. S. (2010). Patterns of hybridization in plants. Perspectives in Plant Ecology, Evolution and Systematics, 12(3), 175-182. doi: 10.1016/j.ppees.2010.02.002

Williams, D. M., \& Ebach, M. C. (2007). Foundations of Systematics and Biogeography. Springer Science \& Business Media. (Google-Books-ID: oEYxbegpXS4C)

Wimsatt, W. C. (1987). False Models as a Means to Truer Theories. In M. H. Nitecki \& A. Hoffman (Eds.), Neutral models in biology. Oxford University Press.

Wimsatt, W. C. (2007). Re-engineering philosophy for limited beings: piecewise approximations to reality. Cambridge, Mass: Harvard University Press.

Winsberg, E. (2018). What does robustness teach us in climate science: a re-appraisal. Synthese. doi: 10.1007/s11229-018-01997-7

Zhaxybayeva, O., \& Doolittle, W. F. (2011). Lateral gene transfer. Current Biology, 21(7), R242-R246. doi: 10.1016/j.cub.2011.01.045 